\title{
Perspective to Bredella MA, Chung CB. Diversity and perception of equity and respect in the Society of Skeletal Radiology.Skel Rad;2021
}

\author{
Mark E. Schweitzer ${ }^{1}$
}

Published online: 30 October 2021

(c) ISS 2021

There is a senior African American urologist who has spent his lifetime, providing medical care to the citizens of Detroit. He remains quite active, and is still an excellent physicianbut perhaps somewhat less excellent than he was a decade or two earlier. He realizes this, and would like to retire but is concerned that many of his patients will fall out of the medical system. Prostate cancer is more frequent in black patients [1], and he is worried that many of his patients would not feel comfortable seeing a physician from a different background.

I was once interviewing a young man for a residency position. As he leaned in to shake my hand, I noticed that he had the suit manufacturer tag still sewn on the end of the sleeve of his jacket. I assumed this might be the first time he had worn a suit and he thought that the suit tag like the "Levi's" tag on jeans was part of the style. It was clear to me, he had little guidance for residency interviews and taking a holistic approach; I felt like he deserved a high score.

Now, running a medical school, I note that the common (US) medical school application asks what type of job the applicant's parents hold. Of what import is that? The AAMC stays that it should be used as a yardstick for how far the student has come. I can't help but think it biases nearly all who read it.

Bias is pervasive in our society. It is pervasive in patients. It is pervasive among treating physicians. It is pervasive among all those assessing us-whether it be a grant reviewer, an editor, or a promotions committee [2]. What the paper by Bredella et al. has shown is that musculoskeletal radiology is no different than the rest of the world [3]. The perception of bias is the equivalent of bias.

Mark E. Schweitzer

mark.schweitzer@med.wayne.edu

1 School of Medicine, Wayne State University School of Medicine, 1241 Scott Hall, 540 E. Canfield, Detroit, MI, USA
The perception of limited opportunities is the equivalent of limited opportunities.

Academe is one of the least open aspects of society. Opportunities as pointed out by Bredella and Chung [3] are preferentially distributed to those who look, and have similar backgrounds to those distributing the tickets up the ladder. These individuals at the top of the ladder are more often male, and much less often persons of color. Another underacknowledged bias, is opportunities are preferentially provided within the assumed hierarchy of institutions [4]. Where one works or trained has a disproportionate effect on one's career prospects.

The first step to overcome these barriers is to acknowledge them, and to be cognizant of our conscious and unconscious biases. The second step is, for those disadvantaged by the system, to receive help. There is all these unspoken rules, pathways and shortcuts that a mentor can help with. Those most in need of mentorship are those least familiar with these silent rules. Unfortunately, those who are underrepresented in medicine are the least likely to have mentors.

The other part of mentorship is nonverbal communication. Black patients want to see the urologist I spoke about above, because of their belief that he understands them and can relate to their life experiences. Hence, they trust him and are more likely to follow his treatment recommendations. The patient doesn't need to say this. Nor does the mentee need to express all their concerns in a spoken fashion.

The resident applicant with the tag on his sleeve needed someone to tell him that the tag should be removed before wear. But more importantly, he needed guidance in preparing for the interview, so as not to put him at a disadvantage relative to other applicants who have the benefit of mock interviews and other forms of advice.

The value of mentors, especially those who have been through what junior academics are going through, cannot be overestimated. Otherwise, the junior faculty member is asked to understand a foreign language s/he has never been 
trained in. You wouldn't climb Mount Everest without a guide. Not only would you be unsuccessful, but to do so would endanger the climber.

Female academics also undergo issues of sexual harassment starting at the earliest stages of their careers. URM faculty undergo stresses related to microaggressions on a daily or weekly basis [5]). Although these behaviors are never acceptable, a knowledgeable guide and sounding post can make a world of a difference in understanding how to respond.

Although most readers are musculoskeletal radiologists, the mentoring process is both specialty, and subspecialty agnostic. However, mentoring is not culturally agnostic. Patients prefer physicians who "look" like them. Although this study found that staff were not concerned with the ethnicity of mentors, there is a body of literature that has concluded that mentees work best with those who have had similar life experiences [6].

I spend a large percent of my time editing. Hence, I like the phrase that reading is a way of doubling one's life. Bias, however has the effect of halving one's life. Mentoring can narrow this difference, although its unlikely to bring it to unity.

Although blessed with several mentors, I often wish I had better mentorship. In my current position, decisions are made from a lonely perch. Everyone needs mentoring and this survey glaringly reinforces that need. Our sponsoring societies should initiate formal programs to help with this. Otherwise, we will perpetuate the same maldistributions that led to the issues highlighted by Bredella and Chung, I would be first in line to help. And I would be the second in line to ask for help myself.

\section{Declarations}

Ethics approval and consent to participate This article does not contain any studies with human participants performed by the author.

Conflict of interest The author declares no competing interests.

\section{References}

1. Merrill RM, Brawley OW. Prostate cancer incidence and mortality rates among White and Black men. Epidemiology. 1997;8(2):126-31.

2. Check Hayden E. Racial bias continues to haunt NIH grants. Nature. 2015;527:286-7. https://doi.org/10.1038/527286a.

3. Bredella MA, Chung CB. Diversity and perception of equity and respect in the Society of Skeletal Radiology. Skel Rad. 2021.

4. Schweitzer, M. The bigotry of pedigree. J Magn Reson Imaging. 2021;54:685-685.

5. Clark US, Hurd YL. Addressing racism and disparities in the biomedical sciences. Nat Hum Behav. 2020;4:774-7. https://doi.org/ 10.1038/s41562-020-0917-7.

6. Liang B, West J. Youth mentoring: do race and ethnicity really matter. Res Action. 2006;9:3-22.

Publisher's note Springer Nature remains neutral with regard to jurisdictional claims in published maps and institutional affiliations. 